\title{
InVesa 1.0: The Conceptual Framework of Interactive Virtual Academic Advisor System based on Psychological Profiles
}

\author{
Ahmad Sofian Shminan \\ Faculty of Cognitive Sciences and \\ Human Development \\ Universiti Malaysia Sarawak \\ 94300 Kota Samarahan, Malaysia \\ sasofian@unimas.my
}

\author{
Lee Jun Choi \\ Faculty of Cognitive Sciences and \\ Human Development \\ Universiti Malaysia Sarawak \\ 94300 Kota Samarahan, Malaysia \\ cljun@unimas.my
}

Mohd Hardyman Barawi

Faculty of Cognitive Sciences and

Human Development

Universiti Malaysia Sarawak

94300 Kota Samarahan, Malaysia

bhardyman@unimas.my

\author{
Wan Norizan Wan Hashim \\ Faculty of Cognitive Sciences and \\ Human Development \\ Universiti Malaysia Sarawak \\ 94300 Kota Samarahan, Malaysia \\ whnoriza@unimas.my
}

\author{
Harisson Andy \\ Faculty of Cognitive Sciences and \\ Human Development \\ Universiti Malaysia Sarawak \\ 94300 Kota Samarahan, Malaysia
}

\begin{abstract}
Interactive Virtual Academic System Prototype (InVesa) is a conceptual automated system dedicated to students where a theory of personality test, Holland Code (RIASEC) is integrated to aid students in selecting the ideal elective subjects for their Cognitive Science course. With InVesa, rather than giving alerts to academic advisors, students are assigned personalized advice by the system on the recommended elective subjects based on their RIASEC result. A student may choose to accept a list of subjects' recommendations from the system or to retake the RIASEC test until they are satisfied with the suggested subjects provided by the system. In addition, students with less time meeting their academic advisors to consult on their subject enrolment may avoid general issues that are common in the standard appointment registration system, such as multiple registrations and long queues when scheduling an appointment. It can be concluded that the proposed application meets the requirements. The proposed application provides a convenient and efficient solution to gain the required information and will benefit the targeted users, which achieves and fulfills the forth of Sustainable Development Goals (SDG) of Quality Education for better education quality for all in terms of gender, age and status.
\end{abstract}

Keywords-Academic advisor expert system, Cognitive science, Psychological profile.

\section{INTRODUCTION}

It is important for students to make the right decision in selecting their courses especially in deciding upon their major that will affect their results and paths in the future for the next few years of their tertiary education. The choices they make define their future careers and determine the nature of their specialization in a specific academic domain. Bouauchi and his peers [1] mentioned that students tend to base their career decisions on their preferences and interests, not considering their abilities and the facilities required for a particular major, which sometimes leads to critical consequences and affects the students' performance, psychology and personal life. Not only that, they are also inclined to choose the major courses not because they want it nor like it but merely to follow their friends, as some are quite uncertain of what they want to be in the future. As a result, they start to regret their choices.

Student academic advising is an essential task in educational institutions, especially at the university level. Some students might have a clear path about their future while some are still in doubt and uncertain of what to do. An academic advisor is assigned to every student during their first year to allow students to seek for advice whenever they have doubts or uncertainties, such as about the courses they want to choose. However, this process is quite timeconsuming as the academic advisor will need to understand the students' interest, situation, and current academic results to know what is suitable for the students. The quality of academic advising received by a student is crucial to the overall performance of the student. Good advising yields a good outcome while bad advising will be frustrating and have a damaging effect on students' progress. In order to fulfil the forth Sustainable Development Goals (SDG), which is Quality Education, the development of InVesa is to ensure that the students are able to know more about themselves in choosing the subjects to prevent the loss of interest towards their courses and subjects [2]. This allow students to be able to graduate on time as they do not need to hold back a year due to the inability to catch up on the subjects that are beyond their interest or ability.

A number of researchers [1],[3],[4],[5] identified that the application of academic advising program has huge benefits for improving the quality of students' learning and development outcomes. In many local universities, academic advisory has already been conducted with a computer system to support the academic advisory process. Using information communication and technology (ICT) to sustain the advisory program would allow both students and universities to keep the news of successes of graduates or the dropout percentage up to date. The system also helps in easing the communication between the students and other relevant departments in the university as the data collected can be retrieved from a centralized repository [4]. It enables the monitoring of students to be on track with the graduation time and allows to cultivate student skills in fulfilling the industry needs. The purpose of this system prototype is to propose a conceptual framework of academic advisor system to integrate a psychological instrument profile that enables students to obtain a tailored result based on their career personality profile. The profile is determined based on Holland's Theory of Career in hopes of complementing elective subject selection for students that match with their personality type. Through this method, the students may select subjects that are closest to their personality based on their answers in the RIASEC test. 